\title{
Simple Tests for Food Purity
}

What the Housewife May Do to Detect Adulterations

By S. Leonard Bastin

TROM time immemorial the freshness or otherwise Fof an egg has been a perplexing problem to the housewife. Even at the present time it is probable that the majority of people do not know how to tell whether an egg is good enough until they have broken it. This is strange inasmuch as the method of finding out the condition of eggs is so simple that anyone can follow it; moreover, the test given is one which is relied upon by the trade and may therefore be taken with confidence. All that is necessary in order to carry out the experiment is a dark room in which a candle has been placed. Now take the egg and hold it up between the eye and the light. A new-laid or very fresh egg will show clearly an air space in the larger end between the shell and the lining membrane. If the egs is really new laid this should be very small, for it tends to increase as an egg is kept. All the rest of the surface shown should present a homogeneous and translucent appearance; if the article is positively bad, a number of dark spots will be visible. A glance at the accompanying photographs will readily give an idea of the two qualities. Once the test has been performed there is no reason why anyone should ever be taken in over the egg question. There is little doubt that milk, especially in towns, is still subject to the time-worn practice of adulteration with wa ter. If skillfully done this is not very easy to detect if the mere appearance of the liquid is considered. There is one very simple test which will tell us at once whether the milk is of a good quality and rich with a prope amount of cream. Take a sample of the milk and place it aside in a receptacle; a small tube is good for the purpose. Stir the milk well and then take a thick brigh knitting needle Plung knitting needle. Plunge this to a depth of sevmilk and hold it stead-

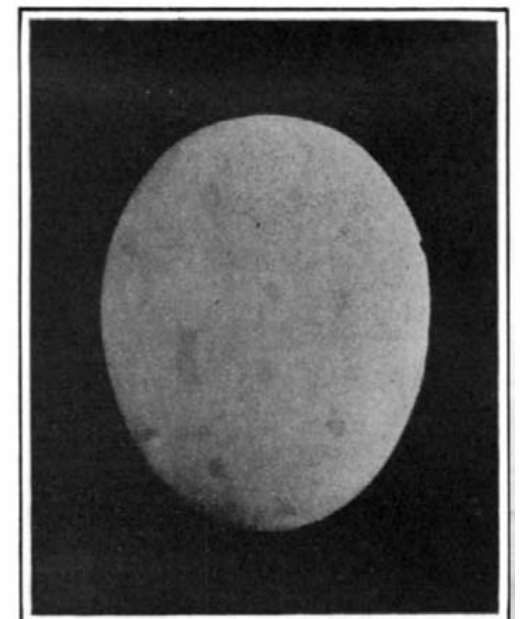

How a bad egg looks in the candle test. ily slanting downward. If the milk is of a rich quality he fluid will slowly gather in a drop at the end of he needle and this will remain, for rather a long time. On the other hand, supposing water has been added the drop will hardly form at all, and even if it should it will not stay but will quickly fall. Poorly fed cows on occasion will give a milk which is so lacking in cream that it will not pass the test under mention. It cannot, therefore, always be said that the milk has been fraudulently watered, although in any case where the result of the experiment shows a poor article it would be well to change one's milkman.

It is idle to deny that there is a great deal of "butter" sold which if it is not margarine, is an ndifferent substitute of doubtful composition. Of course, pure margarine, made as it is from vegetable oils, is at any time better than poor quality butter, although there is of course nothing like the genuine article, on nutritive grounds. Happily it is not a difficult matter to distinguish between margarine and all other butter substitutes, and the pure article. The o-called "spoon" test has been commonly employed by analytical chemists for a long while, and is very reliable. A sample of butter two or three times the size of a pea is placed in a large spoon and heated

over an alcohol burner, or if this is not available an ordinary lamp or gas burner will do as well. Good fresh butter will boil very quietly, producing a number of small foamy bubbles. On the other hand, margarine and most examples of made-up butter will crackle and splutter, making a noise very similar to that which is caused by the placing of a green stick on a hot fire. Still another point of distinction is to be noted if a portion of the sample be placed in a bottle and this is placed in water warm enough to melt the butter. If this is kept warm for half an hour the fat will either be cloudy or entirely clear. In the former case the material is certainly margarine or at any rate not pure butter; in the latter instance however, the article may be adjudged to be of a high standard of purity and freshness. Some of the cleverly made process-butters which are on the market do not always give very definite results but a little study of the matter will enable the experimenter to judge the extent of the adulteration of which he is the victim.

of the commonly used breakfast beverages there is little doubt that coffee is the most widely adulterated. Fortunately, again, there are some simple tests by means of which anyone may determine the character of the article which he buys. When the admixture of foreign matter

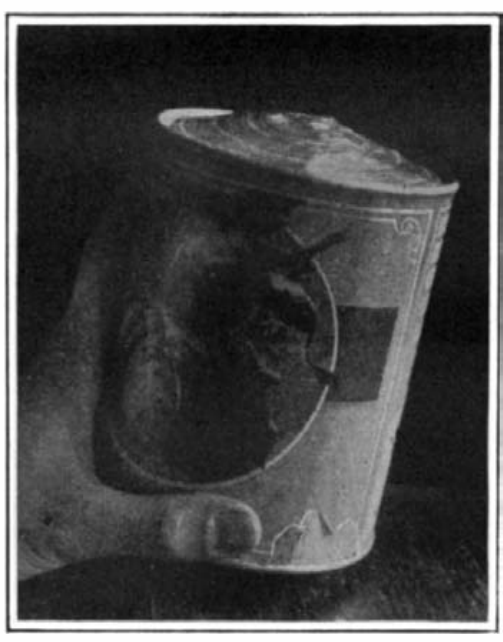

An unsafe package-blown out at the top.

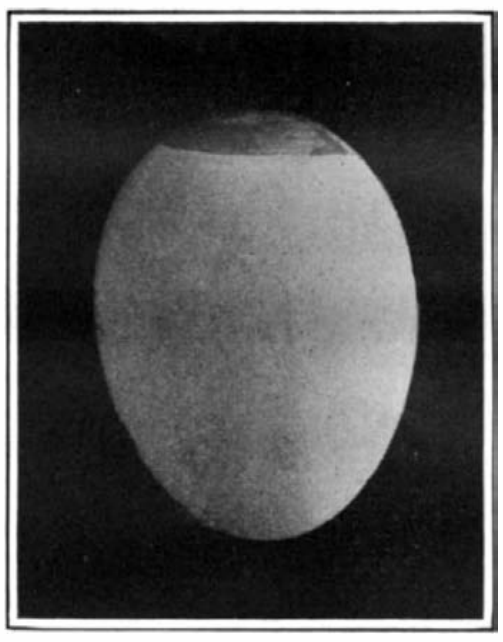

The air space in a new-laid egg. is carelessly done examination of the examination of the grains with a powerful magnifying glass will be sufficient. Absolutely pure coffee should give an entirely uniform appearance, but the presence of adulterants which may take terants which may take the form of groun peas, beans or a host of other articles is readily observed. Chicory which of course may have been openly em ployed is recognized ployed is recognized by its dark and gummy
grain; this is very (Continued on page 439.)

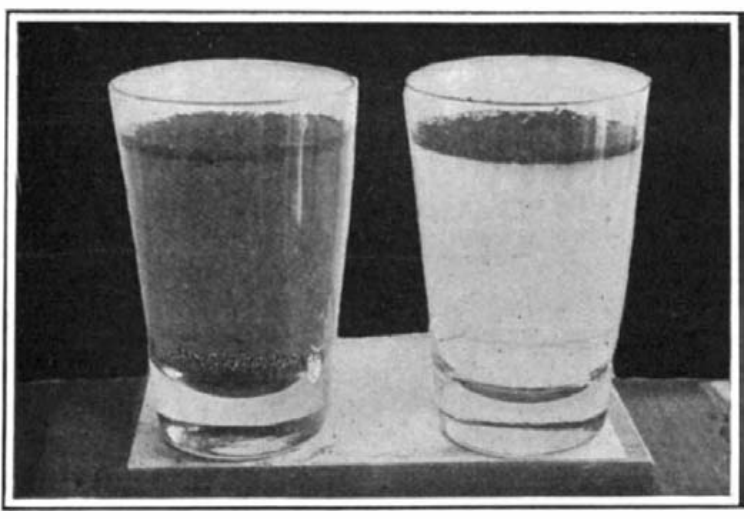

Pure coffee floats, adulterations sink and color the water.

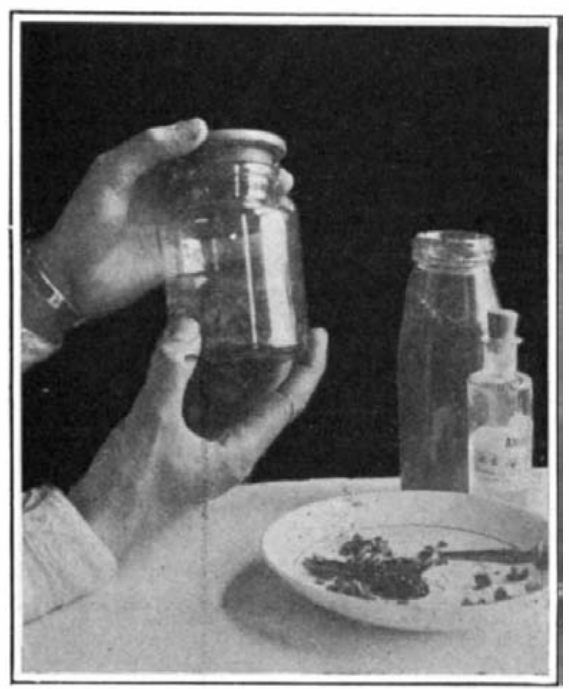

Testing pickles in diluted ammonia to find copper.

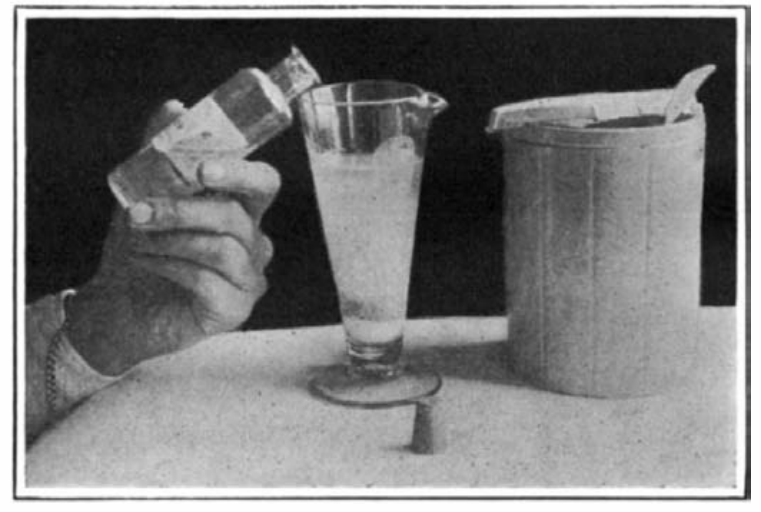

Testing jelly to detect the presence of glucose.

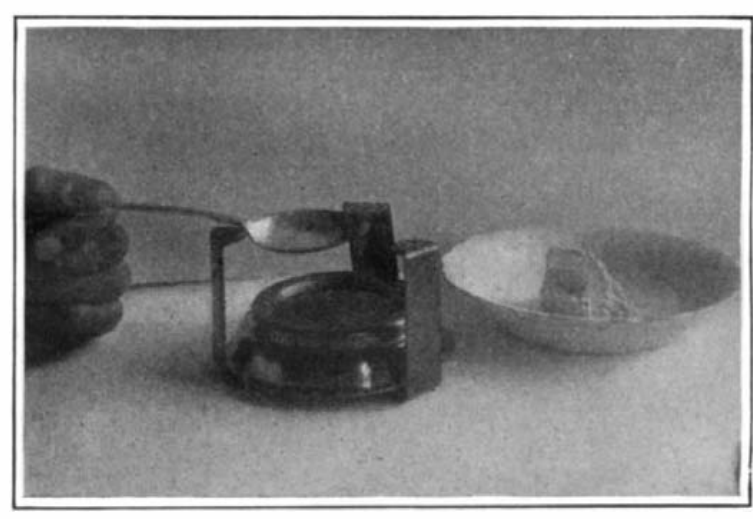

Pure butter boils quietly ; margarine sputters.

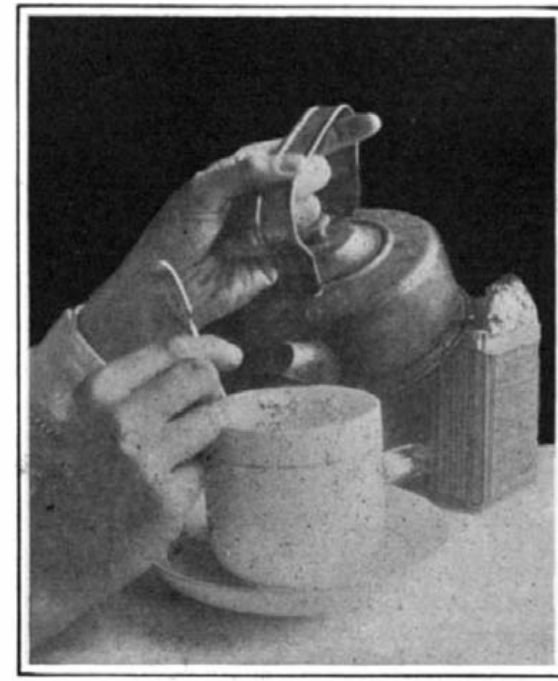

If it thickens, the cocoa is adulterated.

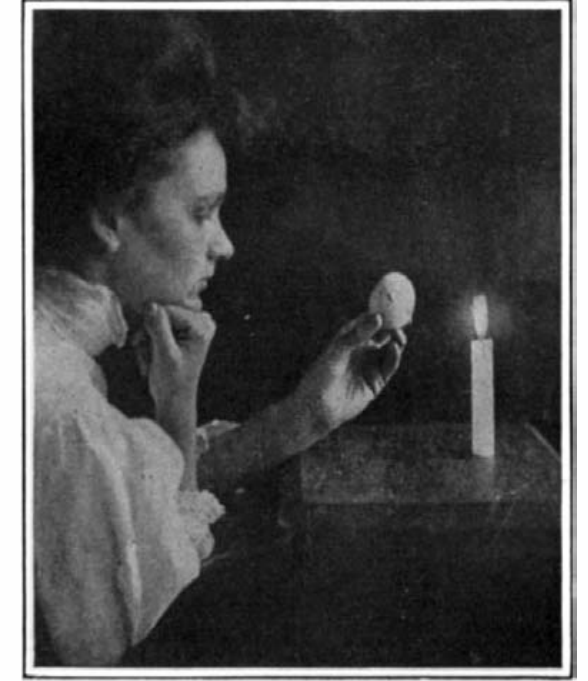

The candle test for eggs.

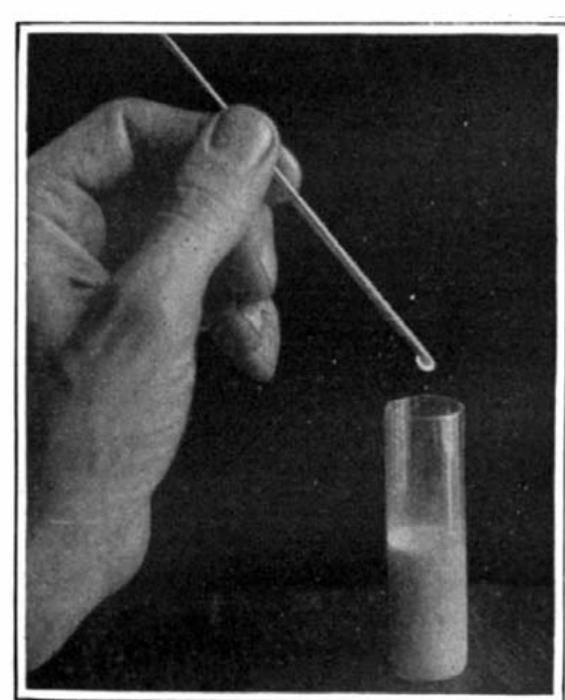

A knitting needle makes a good milk tester.

SIMPLE TESTS FOR FOOD PURITY. 
tion for the anti-torpedo guns and possibly to the mounting of larger weapons for this purpose. Of the ships of the have just been asked, no details are known, but it is believed they will be similar to the "King George" class. It is probable that next year's ships will be of an entirely different type-smaller, and armed with six 15-inch and a number of 9.2-inch guns.

Simple Tests for Food Purity

harmful if it is present in large quant1 ties. Further, nearly all the adulterants employed present a shiny appearance, whereas coffee always looks somewhat dull. A more rapid way of testing any kind of ground coffee is that pictured in an accompanying illustration. Take a tumbler of water nearly full to the brim and scatter about half a teaspoonful of the grains upon the surface of the liquid. Pure coffee contains a large amount of oil and on this account the grains will float with a very few exceptions. Pracsink to the bottom of the tumbler. The presence of chicory in the sample is at ing of the water a deep brown shade. If the tinting is very intense chicory has been added to a positively unwholesome extent. Pure coffee grains will not color cold water, at any rate not until the passing of a considerable interval. In these experiments it is interesting to in clude a few samples of the so-called coffee substitutes, many of which will be shown to contain a large amount of coffee and this in spite of the assertions of the manufacturers.

The only means by which illicit addi tions to tea can be detected is by an examination of the dried leaves after one has become fully acquainted with the genuine article. Leaves of many kinds nection, of which those of the wild plum are perhaps the most commonly used Nowadays, however, at the place of it production tea is so cheap that it scarcely will pay the manufacturer to do much in the way of adulteration. Cocoa is
rather different, however, and there is rather different, however, and there is substance are sadly behind what they should be in the way of quality. Some form or other of starch is a very favorite adulterant with certain sections of the trade. This may be at once detected
if about a teaspoonful of the powder is if about a teaspoonful of the powder is placed in a cup and boiling water is
added. If any starch is present the liquid shows a very marked thickening, a happening which should not be noticeable to any extent in the genuine cocoa essence. A much more harmful adulterant is the addition of cocoa shell; unfortunately the presence of this is not very easily discovered save by the help of a lessly ground it may impart a slight grittiness to the mixture, though of course the skilful manufacturer will take great pains to avoid this.

There are perhaps no articles of food which are more commonly adulterated than jams and jellies. It is not an exag. material sold of this nature is simply the fruit named on the label embodied with pure sugar. Most of the adulterants such as those used for coloring and add ing to the bulk of the jam are fairly harmless, though none is of course desirable. Starch is a very common adulterant in jam though owing to the cloudy properties which it would give to a clear jelly it cannot be used with much effect in this article. In the case of jam it is
impossible to detect its presence without a small test. Dissolve a teaspoonful of jam in half a teacupful of hot water. Through a piece of muslin strain away
any solid matter which is left. Now add any solid matter which is left. Now add
drop by drop a solution of potassium permanganate until the mixture is prac tically decolorized. In some cases of ild can hardly affect the final stages of the test. When the liquid has quite cooled down add a single drop of tincture of lodine and if any starch is present the valued produced in the United States, solution will turn a decided blue color duction at $\$ 52,797,973$. In 1900 the proEven more commonly used than starch is 1905 it was 31,675,257 barrels, in 1906 it \begin{tabular}{l|l} 
glucose, and to determine the presence & was $51,000,445$ barrels, \\
of this adulterant a slightly different test & was $52,910,925$ barrels.
\end{tabular} is necessary. Again the same quantity jam or jelly should be dissolved in will be necessary to strain away the insoluble matter as before. Now allow the add an equal amount or possibly a little more of strong alcohol. In order that the served it is as well to carry out the experiment in a glass vessel. If the sample precipitation except perhaps the smallest mount of proteid bodies. On the other and should glucose have been employe in the manufacture a cloud of dense solution, and finally settles down at the bottom of the tumbler. This may be as been used as an adulterant.

In order to render the appearance of reater or less extent, is frequer, to a loyed in the preparation of pickles. every case, for the practice of boilin the pickles in copper jars is quite sufficient to account for its presence. Scaldopper a fact that should be noted by very cook. Even when only present to urious as of course it is a rank poison.
Pickles of a very bright green color should always be suspected and put of the material with a fork until it is well crushed, and then place the materia tion composed of ammonia and water in the whole well copper the ammonia turns a blue color beans, spinach, etc. In some articles of alarming extent. A very interesting experiment to detect its presence is one strong corrosive which of course must be from contact with the skin or clothes. sample of the vegetables and place aspoonful in a teacup; add thirty drop ove in a saucepan containing boilin up and keep the whole thing boiling for thenty minutes. Stir the mixture all the f the time stated drag out the nail, when copper has been used with the vegeheavily plated with that metal.

A final word on the subject of canned goods may not be out of place. These laws controlling their preparation are ightly stringent. Still now and again, rong with a reason something goes the external appearance of the package. The top or the bottom appears more or
less "blown out" and when this is the ase even to a small extent the contents There is always grave risk attending the consumption of articles contained in un-

\section{Major John Burger Waring}

AJOR JOHN BURGER WARING,
brother of Col. George E. Waring ied on October 30th at the age of sevknown as a pioneer steel pen maker. The wo types of pens invented by him wer Washington medallion. During and the civil ar he invented an improved device for piking cannon. Enlisting as a lieutenin the Fourth Missouri Cavalry, he athe the rank of major in the Ordented an apparatus for removing silk any other mechanical devices. All told

$\mathrm{N} 1909,65,399,889$ barrels of cement small extent this mineral is highly in of imported canned goods such as peas, Deople will be interested to try it. Mash almost always shown by an alteration in

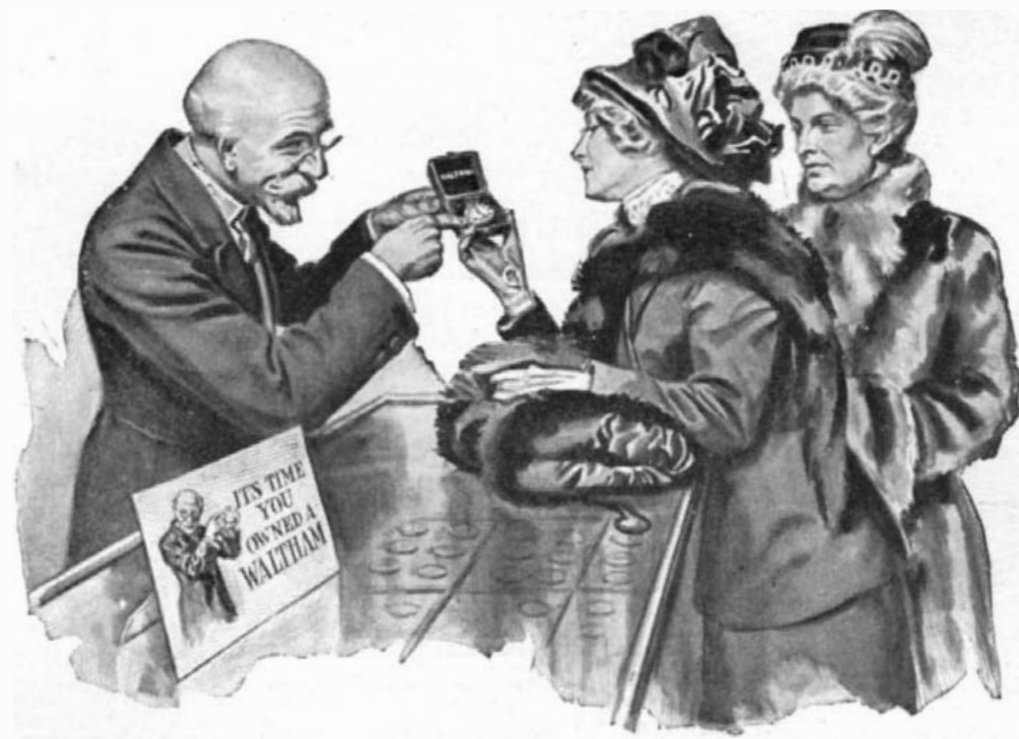

Planning the holiday gift with a Waltham Jeweler is a mutual pleasure. The shopper delights in the beauty and design of the Waltham Watch Models. The experienced jeweler knows the inward perfection of Waltham construction.

\section{WALTHAM}

\section{WATCH}

For over three generations Waltham has stood for the highest expression of the Watchmaker's art. High grade Waltham movementsup to the Premier Maximus at \$250, the watch de luxe of the world-are invariably keeping anditier of nels ol exquiste design and wormanshe, combined with timehigh grade watch in all popular sizes, men's or women's. Ask your Jeweler.

Handsome booklet describing various Waltham move
ments and full of valuable watch lore, free on request.

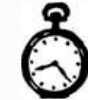

WALTHAM WATCH COMPANY

Waltham, Mass.

In Easily Made High Frequency Apparatus

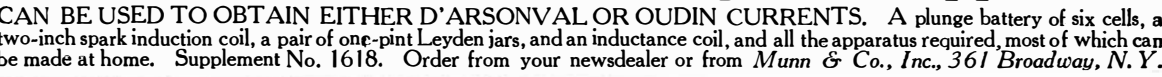

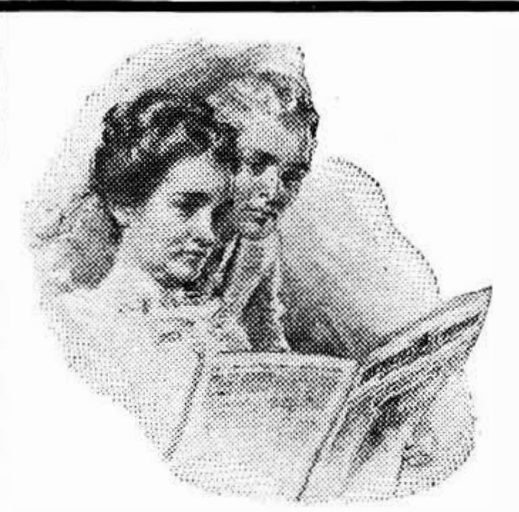

Your Family-

If your family is worth the best you can give in house and food and clothes, is it not worth the best reading as well ?

Subscribe now - to-day - and get all the issues for the remain ing weeks of 1911 Free. The Subscription Price now is
only $\$ 1.75$; on January 1 , 1912 , it will be advanced to $\$ 2.00$.

\section{The Youth's Companion}

$T_{k}$ Cantest

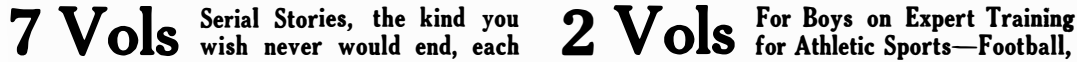
selling for $\$ 1.50$ in book form

2 Vols $\begin{gathered}\text { Articles by Famous Men and } \\ \text { Women. }\end{gathered}$ vention, Biography.

8 Vols $\begin{gathered}\text { Each containing some thirty } \\ \text { complete stories-Adventure, }\end{gathered}$

3 Vols Current Events, The Doctor's eekly Counsel, Science, Wr

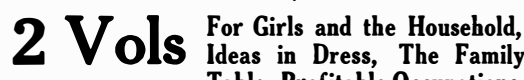
And not less than 6 other Volumes of good reading, including One-Minute Stories, Talks
to Girls, Anecdotes, the Children's Page, etc. Full Prospectus for 1912 sent Free to

\section{The Free Issues} HOW TO GET THEM

Every New Subscriber who at once cuts out and sends this slip (or mentions this paper) with $\$ 1.75$ for The
Companion for 1912 receives FREE

All the issues for the remaining weeks of 1911 , including the beautiful Holiday Numbers; also The Companion's Calendar for 1912, lithographed in ten colors and gold. Then The Companion for the 52 weeks
of 1912 . Your last chance to get The of 1912. Your last chance to get The Companion for $\$ 1.75$. Subscribe to-

THE YOUTH'S COMPANION BOSTON, MASS.

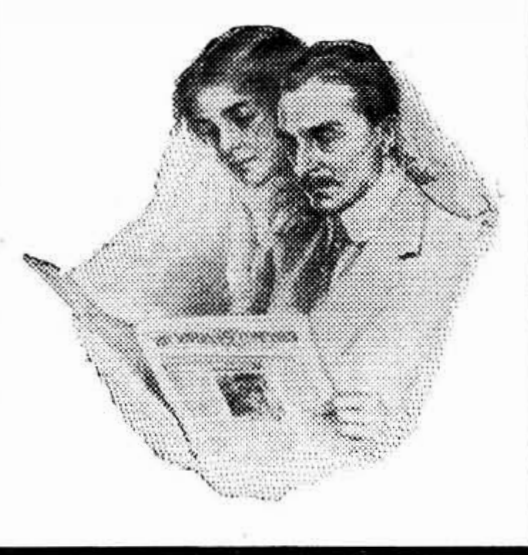

